\title{
FATIGUE FAILURE ON DRILLING PIPE THREAD: A CASE STUDY ON DRILL PIPE SS105
}

\author{
Afriansyah ${ }^{1,2 *}$,Hendri Chandra, ${ }^{1}$ Diah Kusuma Pratiwi ${ }^{1}$, AneKa Firdaus ${ }^{1}$ \\ ${ }^{I}$ PT. Pertamina Drilling Project South Sumatera,Prabumulih, South sumatera, Indonesia \\ ${ }^{2}$ Department of Mechanical Engineering, Sriwijaya University, 30662 Indralaya, South Sumatera, \\ Indonesia \\ *Corresponding author: afri.praboe@gmail.com
}

(Received: 1 Ocotber 2020; Accepted: 13 November 2020; Published on-line:31 November 2020)

\begin{abstract}
This study presents a case study investigation on failure analysis of drill pipe during the drilling operation and to establish a general understanding of fatigue failure with experiments and several tests. Drill pipe load comprises tensile, compression, bending, hydrostatic pressure, and vibration, which causes damage due to fatigue failure to the drill pipe. The method involves subjecting a 2 in length and nominal diameter 3.25 in connection NC50 19.5 ppf drill pipe to predetermined caused failure by experimental tests and analysis. Mechanical examination such as tensile test and hardness test, and metallurgical examination such as spectrometry, fractography, SEM, and EDX testing are conducted. The result shows that the cause of failure on the thread drill pipe was due to fatigue failure. It showed by the presence of microcracks, which accumulated from the load in the drill pipe. Besides, propagation of the crack at critical depth resulting in failure during drilling operations.
\end{abstract}

KEYWORDS: Thread drill pipe, Failure analysis, Fatigue failure

\section{INTRODUCTION}

In the world of drilling both oil, gas, and geothermal drilling are known equipment which is supported drilling operation namely drilling pipe, to add the length of depth connected to the bottom hole assembly or BHA of a string such as a collar, stabilizer, or HWDP [1-5]. Besides, the drill pipe serves as a place for fluid flow extraction pumped by mud from the surface to the hole.

Drilling operations encounter various loads such as tensile, compression, bending, hydrostatic pressures, and vibrations [6]. Besides, their magnitude, position, and duration occur continuously and tend to vary, therefore, the drill pipe often fails during operations such as twist off, and leakage due to washing out. These lead to significant losses due to non-productive time and additional operational costs. There are some identified places for failure on drill pipes [5] which include screw connections on the inside, outside, and upset where the stress concentration is higher. These places have good potential for cracks. These places have good potential to start cracks. Several mechanical tests must be carried out between micro fractography, tensile testing, and testing of violence

Previous research discussed various conditions of damage associated with drill pipes as follows: Wang reported the cause of longitudinal cracks due to heat using 21 drill pipe tool joints [7]. The results showed that frictions due to heat check cracking, bite tong, and damage to the thread are the initial signs of potential damage. However, heat check cracking is a mechanism for crack initiation, and not a propagation mechanism, which mainly stresses 
corrosion, and sulfide of the corrosive media. While Liu tested the axial crack on drill pipe which is caused by corrosion as shown by spectrum, XRD, macro, and microanalysis [3]. From the test data, the residual stress is circular which decreases with an increase in temperature to $500 \mathrm{oC}$, with circular residual stress of $61 \%$ from the critical value due to corrosion. Therefore, the second tempering tends to effectively reduce the circular residual stress of the drill pipe body and avoids the appearance of axial cracks.

The main reason for the washout leak pipe is its poor quality with uneven taper configuration from internal upset [4], which depends on sudden geometric changes and the resistance of materials which are low to corrosion, stiffness, and high slope or dog-leg angles. Furthermore, under the influence of axial tensile loads, the stress transition zone is significantly damaged than the tool joint and other parts $[1,2,8]$. Finite element stress analysis was conducted under axial and bending loading on drill string threaded joints [9], the results indicate a clear trend to increase SCF as the thread size increases. The torsional force of the connection and the torque during the connection is related to the unit coefficient of friction torque, simply multiplying by the coefficient of static friction or by the wet friction coefficient [10]. The cause of failure when connecting the drill pipe is fatigue and excessive torque load and this is not affected by corrosion during connection but contributes to other failures [11,12]. Fatigue failure and excessive load are found in the LET section (last Engaged Thread) which results in an increase in the stress concentration factor due to different load and stress distributions. The load that is applied to the thread is not uniform. The smallest load is at the end of the pin and middle of the teeth [13]. The procedure to study had been conducted by a researcher it is the same procedure as a mechanical review of failure (visual, Charpy impact, and tensile test) and metallurgical examination (optical microscope, SEM, Fractography) [6]. This study aimed to identify fatigue failure on drill pipe during drilling operation with an initial crack due to corrosion.

\section{MATERIALS AND METHOD}

The materials used in the present study include drill pipe at pin area about 2 in length and nominal diameter 3.25in connection NC50 19.5 ppf, respectively, Rockwell's hardness indentation-testing machine, Scanning electron microscopy with EDX (Energy Dispersed XRay), Composition testing material, etc. The pipe material selected was SS105 (based on a PMC source).

The method for this study was to use an experiment in the laboratory to examine the fractured part of the drill pipe. It used compares test data carried out in the laboratory with standard material properties specifications. Failure analysis of drill pipes is carried out in the laboratory of metallurgy at Sriwijaya University in Palembang with some testing on the specimen, namely tensile test, hardness test by Rockwell system, The crack surface was observed by visual examination and scanning electronic microscopy (SEM) and EDX (Energy Dispersive X-Ray, and fractography test for the examined microstructure of drill pipe. The sample is from Pertamina drilling services. Before examined, the Fracture part was cleaned and prepared for analysis with etching.

\section{Result and discussion}

\subsection{Faults Macro Analysis}

Fig. 1 shows that the failure occurs in the area close to the drill pipe thread. Besides, on the inner surface of the fault appears fatigue fracture at various points occurring up to $3 / 4$ of the 
thickness, which the remaining part is a static fracture. This is located outside and marked with a groove residual example of $\mathrm{A}, \mathrm{B}$, and $\mathrm{C}$.

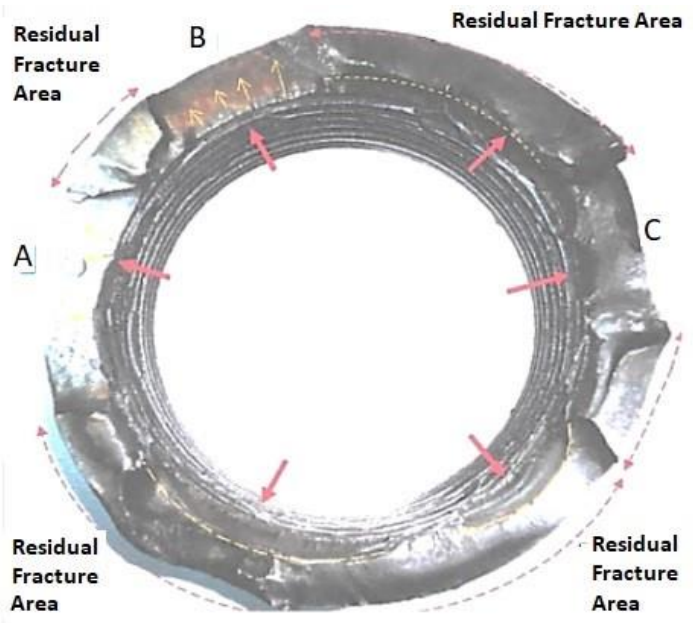

Fig. 1. Macro mapping frictional drill pipe

\subsection{Mechanical Properties}

The chemical composition of the drill pipe is seen in table 1 . The analysis results show that the main chemical percentages of the ingredients are $\mathrm{Fe}, \mathrm{Cr}$, and $\mathrm{Mn}$, which are used for comparison as presented in Table 1.

Table 1. Results of analysis of chemical composition (spectrometer)

\begin{tabular}{|c|c|c|c|c|c|c|c|c|c|c|c|c|c|c|c|c|}
\hline Element & $\mathrm{Fe}$ & $\mathrm{C}$ & $\mathrm{Si}$ & $\mathrm{Mn}$ & $\mathrm{P}$ & $S$ & $\mathrm{Cr}$ & Mo & $\mathrm{Ni}$ & $\mathrm{Al}$ & Co & $\mathrm{Cu}$ & $\mathrm{Nb}$ & $\mathrm{Ti}$ & V & W \\
\hline Result & $\begin{array}{c}95 . \\
9\end{array}$ & $\begin{array}{c}0.4 \\
9\end{array}$ & $\begin{array}{c}0.3 \\
1\end{array}$ & $\begin{array}{c}1.0 \\
7\end{array}$ & 0.03 & $\begin{array}{c}0.0 \\
2\end{array}$ & $\begin{array}{c}1.1 \\
1\end{array}$ & $\begin{array}{c}0.3 \\
4\end{array}$ & $\begin{array}{c}0.1 \\
6\end{array}$ & $\begin{array}{c}0.0 \\
3\end{array}$ & $\begin{array}{c}0.4 \\
2\end{array}$ & $\begin{array}{l}0 . \\
2\end{array}$ & $\begin{array}{c}0.0 \\
8\end{array}$ & 0.0 & $\begin{array}{c}0.0 \\
4\end{array}$ & 0.0 \\
\hline $\begin{array}{l}\text { Standar } \\
\mathrm{d} \quad(\mathrm{SS} \\
105)\end{array}$ & & $.25-0.35$ & & $\begin{array}{c}0.4- \\
1\end{array}$ & $\begin{array}{c}0.01 \\
5\end{array}$ & 0.1 & $\begin{array}{c}0.9- \\
1.3\end{array}$ & $\begin{array}{c}0.3- \\
0.6\end{array}$ & & & & & & & & \\
\hline
\end{tabular}

Table 2. Standards for material based on PMC Sour Handbook

\begin{tabular}{ccccccccc}
\hline Spec & Grade & C & Si & Mn & P & S & Cr & Mb \\
\hline PMC & SS105 & $0,25 / 0.35$ & - & $0,40 / 1.00$ & 0,015 & 0,10 & $0,90 / 1.30$ & $0.30 / 0.60$ \\
Source & & & & & & & & \\
\hline
\end{tabular}

Based on Table 1 and Table 2, in the chemical test, the value of $\mathrm{C}$ exceeds the standard specification limit of $0.496 \%$, with $\mathrm{Mn}$ at $1.07 \%$ and $\mathrm{P} 0.033 \%$. The data shows that the material has properties transformation, with increasing carbon (C) value, which increases the hardness according to the test results obtained.

From Fig. 2, we conduct a hardness test for the part of failure with the Rockwell hardness test and tensile test. Before the test, we separate material into two samples are sample A and B, each sample we conduct test hardness test, Hardness testing is carried out with two tests, namely carried out on the edge of the fault and in the middle of the fault, each of which is carried out five points. 


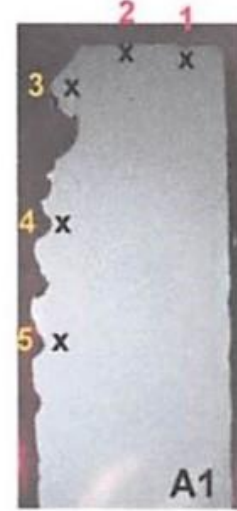

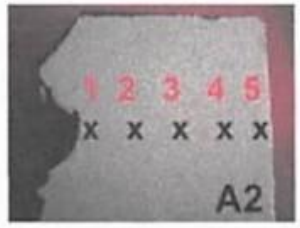

SAMPEL A

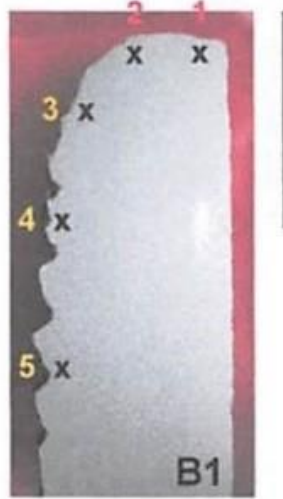

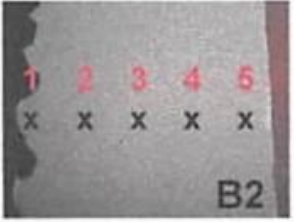

SAMPEL B

Fig 2. Sample for hardness test

Tables 3 and 4, shows the hardness and tensile tests carried out at several points of the sample. Table 5 showed standard material hardness and tensile strength. The result of hardness testing showed that several points have exceeded the limits of Hardness HRC.

Table 3. Hardness test results

\begin{tabular}{ccccc}
\hline \multirow{2}{*}{ No. } & \multicolumn{4}{c}{ Value of Hardness HRC } \\
\cline { 2 - 5 } & Sampel A1 & Sampel A2 & Sampel B1 & Sample B2 \\
\hline 1. & 35,5 & 33,3 & 34,4 & 32,2 \\
2. & 31,0 & 32,6 & 31,5 & 32,0 \\
3. & 31,5 & 32,2 & 31,0 & 31,5 \\
4. & 31,5 & 34,4 & 32,5 & 32,2 \\
5. & 33,3 & 36,4 & 31,5 & 35,0 \\
Average & 32,5 & 33,7 & 32,2 & 32,6 \\
Standard & $29-31$ & $29-31$ & $29-31$ & $29-31$ \\
\hline
\end{tabular}

The result showed based on table 3, for sample A1 found average Hardness number is 32.5 HRC with maximum hardness at point 1 (at the top sample). For the sample, A2 found the average hardness number is 33.7 with maximum hardness at point 5 (at edge sample). For sample, B1 found average hardness number is 32.2 with maximum hardness at point 1 (at the top sample) and for sample, b2 found average hardness number is 32.6 with maximum hardness at point 5 (at edge sample). In conclusion, the hardness of the fractured part is more than the hardness standard material. It is related to the \% $\mathrm{C}$ material from the composition test before.

Table 4. Static tensile testing results

\begin{tabular}{cccc}
\hline Sample & $\begin{array}{c}\text { Yield } \\
\text { strength }(\mathrm{Mpa})\end{array}$ & $\begin{array}{c}\text { Tensile } \\
\text { Strength }(\mathrm{MPa})\end{array}$ & $\begin{array}{c}\text { Elongation } \\
(\%)\end{array}$ \\
\hline A & 882 & 1019 & 17 \\
B & 892 & 1020 & 18 \\
Standard & $724-827$ & $793-965$ & \\
PMC Source & & & \\
\hline
\end{tabular}

From the tensile test, at sample a found tensile strength is $882 \mathrm{MPa}$ and at the sample, $\mathrm{B}$ found tensile strength is $1019 \mathrm{MPa}$. Compared to standard tensile and yield strength material, 
Indonesian Journal of Engineering and Science, Vol. 1, No. 1, 2020 Afriansyah et al. we conclude tensile strength samples A and B more than standard. It is related to the increasing $\% \mathrm{C}$ at material.

Table 5. Specifications Standard PMC sour grade SS105

\begin{tabular}{|c|c|c|c|c|c|c|c|c|c|c|}
\hline \multirow{4}{*}{ Grade } & \multirow{2}{*}{\multicolumn{4}{|c|}{ Yield strength }} & \multirow{2}{*}{\multicolumn{4}{|c|}{ Tensile strength }} & \multirow{4}{*}{$\begin{array}{l}\text { Elongation } \\
\text { Min \% }\end{array}$} & \multirow{4}{*}{\begin{tabular}{l}
\multicolumn{2}{l}{ Hardness } \\
HRC Ave. \\
Each Max \\
Max/Min
\end{tabular}} \\
\hline & & & & & & & & & & \\
\hline & \multirow{2}{*}{$\begin{array}{c}\text { Min } \\
\text { Psi }\end{array}$} & \multicolumn{3}{|c|}{ Max } & \multirow{2}{*}{$\begin{array}{c}\text { Min } \\
\text { Psi } \\
\end{array}$} & \multicolumn{3}{|c|}{$\operatorname{Max}$} & & \\
\hline & & $\mathrm{MPa}$ & Psi & $\mathrm{MPa}$ & & $\mathrm{MPa}$ & Psi & $\mathrm{MPa}$ & & \\
\hline SS105 & 105,000 & 724 & 120,000 & 827 & 115,000 & 783 & 140,000 & 965 & API Formula & 29 to 31 \\
\hline
\end{tabular}

\subsection{Analysis Micro-Fracture}

Testing for micro-fracture analysis using SEM (Scanning Electron Microscope) and EDX (Energy Dispersive X-Ray). Testing is done on the fracture surface and the inner surface of the drill pipe. The results obtained from the analysis are as follows

\subsection{SEM and EDX at the surface fracture}

Fig. 3 showed SEM and EDX results on the surface fracture drill pipe. The image clearly shows the "white area" is ferrite. Based on the EDX spectrum, value Fe, C, and O is the highest value on the surface fracture. On the surface, fracture showed there are micro-cracks. Furthermore, there is an iron oxide $(\mathrm{FeO})$ on the surface fracture. It can be formed by element $\mathrm{Fe}$ and element $\mathrm{O}$ based on EDX analysis.

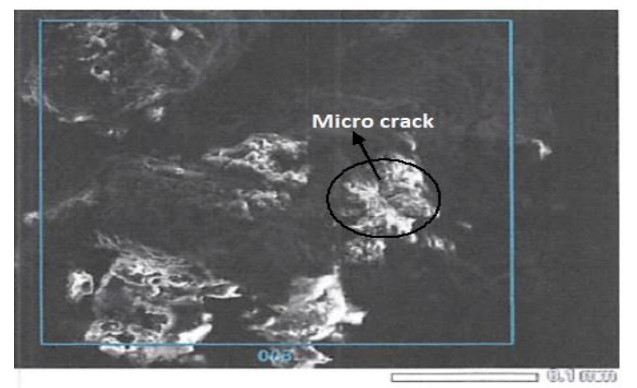

\begin{tabular}{cccc}
\hline Element & \% Mass & \% atom & \% K \\
\hline C & 42.46 & 64.49 & 22.32 \\
O & 19.39 & 22.10 & 18.31 \\
Mg & 0.48 & 0.36 & 0.35 \\
Al & 0.71 & 0.48 & 0.67 \\
Si & 1.35 & 0.88 & 1.62 \\
Ca & 0.47 & 0.21 & 0.90 \\
Cr & 5.16 & 1.81 & 9.01 \\
Fe & 29.0 & 9.48 & 45.43 \\
Mo & 0.98 & 0.19 & 1.35 \\
\hline Total & 100 & 100 &
\end{tabular}

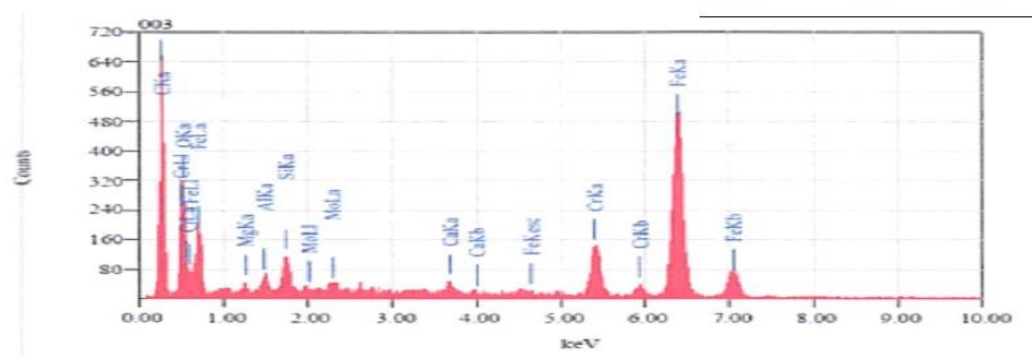

Fig. 3. SEM and EDX at the surface fracture

\subsection{SEM and EDX at the inner surface fracture}

Fig. 3.4 showed SEM and EDX results on the inner surface fracture drill pipe. There are SEM images and EDX graphic charts that showed an element of inner surface fracture. 


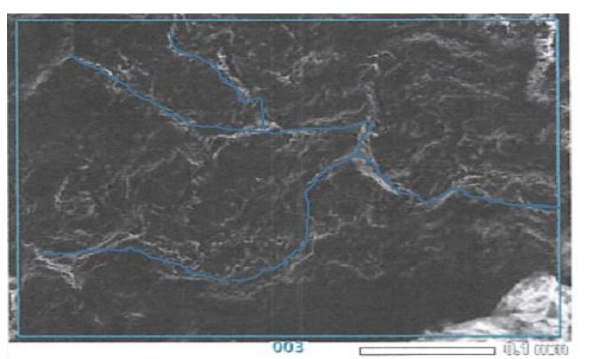

\begin{tabular}{cccc}
\hline Element & \% Mass & \% a tom & \% K \\
$\mathrm{C}$ & 11.80 & 23.10 & 3.20 \\
$\mathrm{O}$ & 37.71 & 55.43 & 45.78 \\
$\mathrm{Si}$ & 0.29 & 0.24 & 0.19 \\
$\mathrm{~S}$ & 0.30 & 0.22 & 0.30 \\
$\mathrm{Fe}$ & 49.42 & 20.81 & 50.05 \\
$\mathrm{Ni}$ & 0.48 & 0.19 & 0.45 \\
\hline Total & 100 & 100 & \\
\hline
\end{tabular}

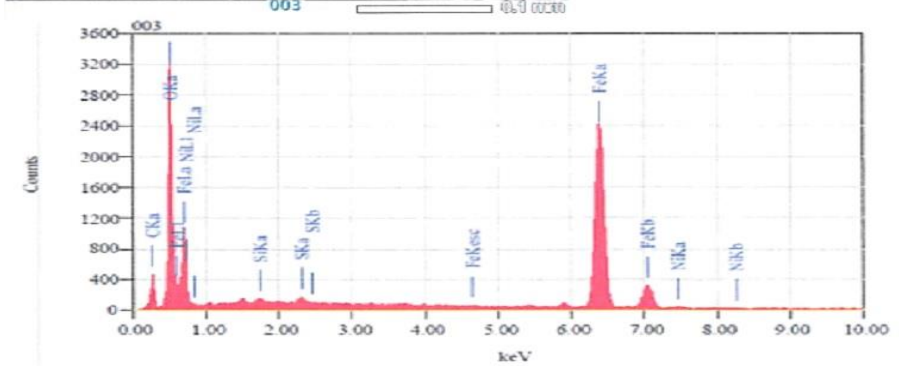

Fig. 4. SEM and EDX Inner Surfaces fracture

The image clearly shows a crack along the grain boundary. Based on the EDX spectrum, value $\mathrm{Fe}, \mathrm{C}$, and $\mathrm{O}$ are the highest value on the inner surface fracture (thread drill pipe). The crack surface is flat and has a grainy texture as a result of changes in orientation of the cleavage planes from grain to grain. Crack propagation is along grain boundaries (intergranular)

\subsection{Fractography testing}

The fractographic analysis is carried out on the failure drill pipe. Fig. 5 showed result fractography on the inner surface drill pipe after 25 times the enlargement is conducted to determine the sign from the initial phase of the fault.

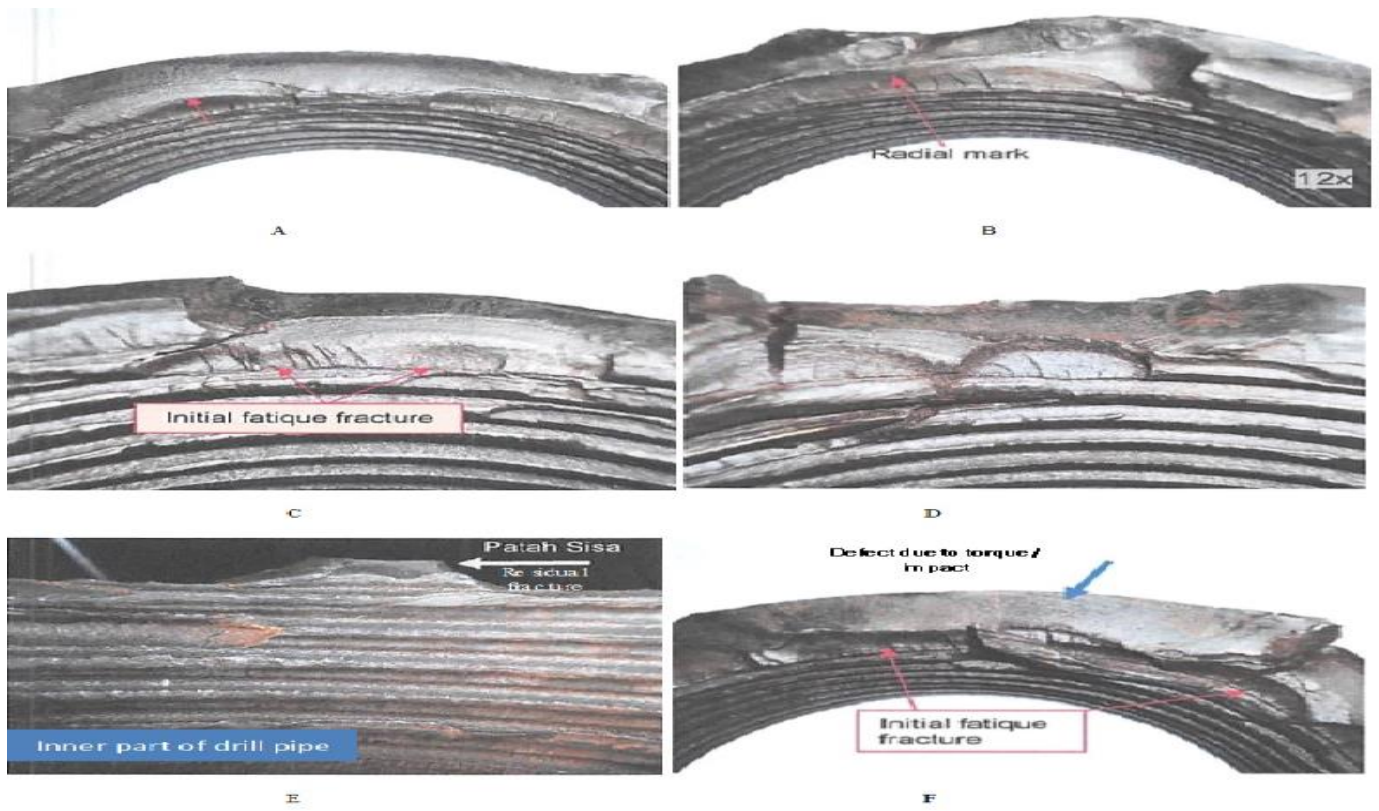

Fig. 5. Result fractography on inner surface drill pipe

Fig. 5. A \& B showed a radial mark on the inner surface of the drill pipe. C \& D showed initial fatigue fracture on the surface fracture. D showed residual fracture on the inner surface. E showed Initial fatigue fracture and defect due to torque/impact. The macro photo on the 
threaded Fig. 5 C, D, and F showed the beginning of the crack starting from the thread's inner leg (C and D). Radial mark on Fig. 5 A and B caused by fatigue fracture. Surface fracture is flat and there is a residual fracture on the surface (Fig. 5E).

Fig. 6 showed Preliminary Macro Crack Photo after enlargement $6 \mathrm{X}$ and 12X. It showed a thread image on a drill pipe connection that has been a failure.
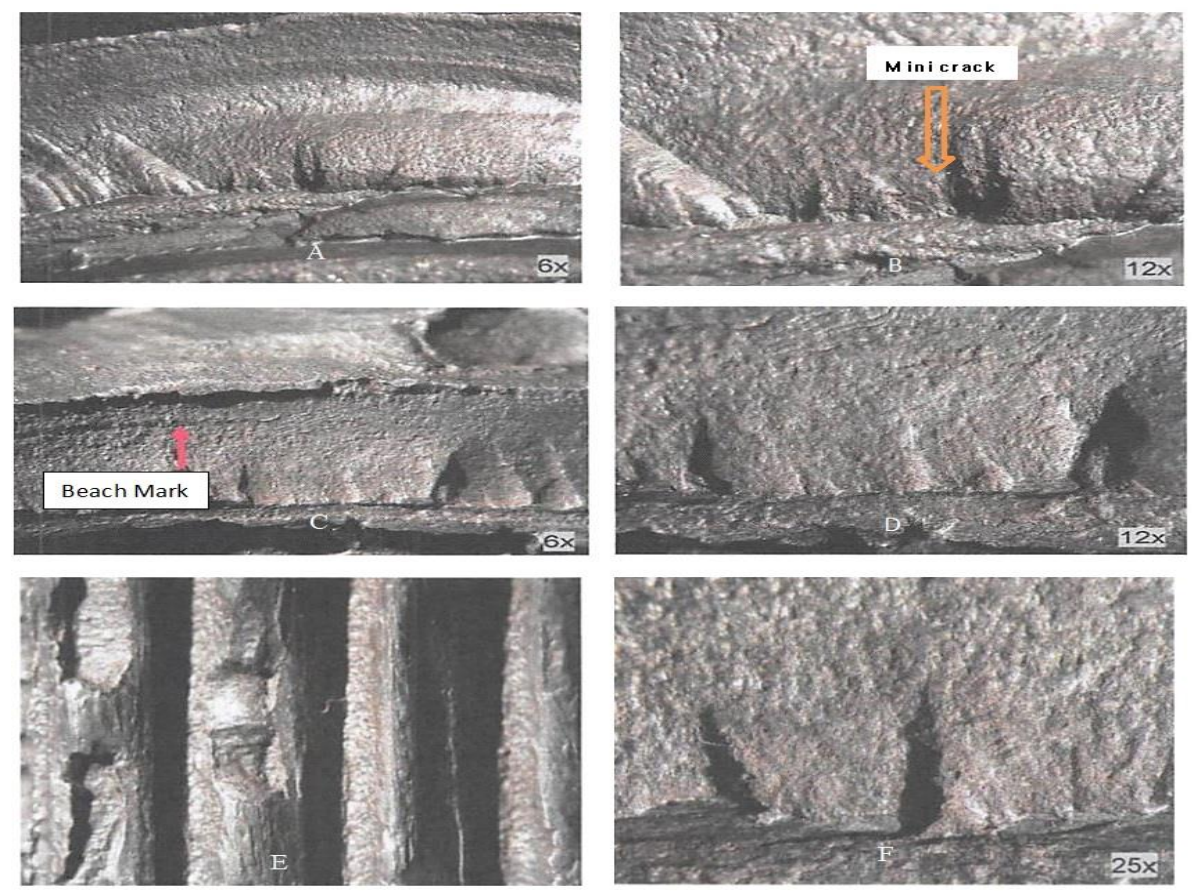

Fig 6. Preliminary Macro Crack Photo (threaded detail)

Fig. 6. A and B showed Preliminary Macro Crack Photo (threaded detail) magnification $6 \mathrm{x}$ and $12 \mathrm{x}$. C and $\mathrm{D}$ showed the beach mark on surface fracture with magnification $6 \mathrm{x}$ and $12 \mathrm{x}$. E and $\mathrm{F}$ showed crack on the thread of the drill pipe with magnification $6 \mathrm{x}$ and $25 \mathrm{x}$.

Macro photo 6A showed part of threaded. Arrow showed a beach mark area. Fig. 6B showed a mini crack on the thread drill pipe. The surface fracture is flat. Therefore, it is a fatigue fracture. Macro photo from magnification from Fig. $6 \mathrm{C}$ and $6 \mathrm{D}$ shows the beginning of the fault starting from the threaded leg, marked with visible beach marks on the arrow. Photo $6 \mathrm{E}$ and $6 \mathrm{~F}$ showed condition thread after fracture after enlargement $6 \mathrm{X}$ and $25 \mathrm{X}$. It showed a fracture from the Last engaged thread (LET). This condition suitable for McDonald's had found [12].

\subsection{Analysis of the Causes of Failure}

From the tensile test, the strength and yield values obtained are above the standard. Similarly, the hardness test shows that the value is above the standard which is caused by the carbon content (C) with an existing value of 0.496 (standard 0.25-0.35) based on the spectrometer test from the sample. The areas surrounded by cracks are seen from fractographic testing where there is a beachmark on the area of the threaded leg, which indicates a failure due to fatigue. Besides, there are corrosive signs in the threaded area which is capable of causing failure. This is seen from the SEM and EDX testing where on the surface of the fault there is a very large $\mathrm{O}(14 \%-28 \%), \mathrm{C}$ (amounting to $22 \%-35 \%)$, and Fe elements (20\%-60\%). While on the inside of the fault surface there is a greater content of $\mathrm{O} 45 \%-54 \%, 3 \% \mathrm{C}$, and $40 \%-50 \% \mathrm{Fe}$ element. This analysis shows that the grey area consists of iron oxide (FeO) and 
residual sediment from drilling mud. Therefore, carbide from iron oxide formed the $\delta$ phase and was placed on the grain boundary resulting in intergranular fracture. Furthermore, failure occurs due to the cumulative torque load when drilling takes place, due to the existing micro crack in the pipe. Besides, the result of drilling fluid flow causes the propagation of the cracks due to the speed and pressure from pumping the drill pipe at 2210 psi. This is capable of affecting the corrosive agent of the Cl-content. The above description shows that the failure of the drill pipe starts from the formation of microcracks in the threaded area, especially in the leg region, which is its weakest point [1]. This is usually caused during the connection of the drill pipe with excessive torque or due to a lack of fatigue resistance on the tool joint. It generates microcrack on intergranular boundary caused by corrosive. The microcrack spreads out on the threads due to the load received by the drill pipe during operations is torsional, bending, and tension. Once formed, the crack begins to extend around the drill pipe at a certain depth, which is accumulated from the load and slope angle during operation which failed due to a decrease in pressure and drilling load.

\section{CONCLUSIONS}

In this study, the following were analyzed the failure due to fatigue on the drill pipe, especially on the thread section, was caused by the initial micro-cracks and its spread which is usually triggered by the amount load received by the pipe during the drilling process. Besides, the fatigue cracks on the threads usually occur on the first threaded or foot. To avoid similar incidents, the following should be conducted: drill pipe inspection according to DS1 standards and the strength of the drill pipe tool joint need to be increased during the manufacturing process with a heat treatment process such as quenching and tempering to eliminate residual stress in the threaded area.

\section{ACKNOWLEDGMENTS}

The authors would like to thank Universitas Sriwijaya for laboratory facilities and financial assistance for this project.

\section{REFERENCES}

[1] Fangpo L and Xin X 2011 Simulation Technology in Failure Analysis of Drill Pipe 12 236-41

[2] Lin Y, Qi X, Zhu D, Zeng D, Zhu H, Deng K, and Shi T 2013 Failure analysis and appropriate design of drill pipe upset transition area Eng. Fail. Anal. 31 255-67

[3] Liu Y, Lian Z, Lin T, Shen Y and Zhang Q 2015 A study on axial cracking failure of drill pipe body EFA

[4] Lu S, Feng Y, Luo F, Qin C and Wang X 2005 Failure analysis of IEU drill pipe wash out 27 $1360-5$

[5] Anon DS-1 volume 3, 2012 Drill Stem Inspection.o.pdf

[6] Zamani S M, Hassanzadeh-tabrizi S A, Sharifi H, Sayed H and Hassan S 2015 SC

[7] Wang X, Li F, Liu Y, Feng Y and Zhu L 2017 PT Eng. Fail. Anal.

[8] Zhu X H 2015 Failure analysis and solution studies on drill pipe thread gluing at the exit side of horizontal directional drilling (Elsevier Ltd.)

[9] Tafreshi A 1999 SIF evaluation and stress analysis of drillstring threaded joints Int. J. Press. Vessel. Pip. 76 91-103

[10] Santus C, Bertini L, Beghini M, Merlo A and Baryshnikov A 2009 Torsional strength comparison between two assembling techniques for aluminium drill pipe to steel tool joint connection Int. J. Press. Vessel. Pip. 86 177-86

[11] Macdonald K A and Deans W F 1995 Stress analysis of drillstring threaded connections using the finite element method Eng. Fail. Anal. 2 1-30 
[12] MacDonald K A 1994 Failure analysis of drillstring and bottom hole assembly components Eng. Fail. Anal. 1 91-117

[13] Chen S, Li Q, Zhang Y and An Q 2011 Finite element analysis of tooth load distribution on P$110 \mathrm{~S}$ conic threaded connections Int. J. Press. Vessel. Pip. 88 88-93 